Revista Médica Sinergia Vol.3 Num:9

Setiembre 2018 pp: 3 - 8

ISSN:2215-4523

e-ISSN:2215-5279

http://revistamedicasinergia.com

\section{COLANGITIS ESCLEROSANTE PRIMARIA}

\author{
(Primary sclerosing cholangitis)
}

\author{
1 Dra. Karla Acuña Vargas \\ Investigadora independiente, San José, Costa Rica \\ acunak872@gmail.com \\ https://orcid.org/0000-0001-5904-3214
}

DOI: https://doi.org/10.31434/rms.v3i9.135

\title{
RESUMEN
}

La Colangitis esclerosante primaria (CEP) es una enfermedad hepática colestásica crónica, caracterizada por inflamación progresiva y fibrosis de los conductos biliares intra y extrahepáticos, El CEP está asociado (60-80\%) con la enfermedad inflamatoria intestinal (EII), principalmente la colitis ulcerosa, y con frecuencia se complica por el desarrollo de colangiocarcinoma. La mayoría de las personas no tienen síntomas (44-56\%), por lo que el diagnostico se les realiza cuando se detectan pruebas hepáticas anormales y/o descubrimiento incidental de conducto intrahepatico dilatado.

PALABRAS CLAVES: colangitis, vesícula biliar, fibrosis, extra hepático, hígado, intestino.

\section{ABSTRACT}

Primary sclerosing cholangitis (PSC) is a chronic liver disease characterized by a progressive course of cholestasis with inflammation and fibrosis of the intrahepatic and extrahepatic bile ducts. PSC is strongly associated $(60-80 \%)$ with inflammatory bowel disease (IBD), mainly ulcerative colitis, and is often complicated by the development of cholangiocarcinoma. Most individuals have no symptoms (44-56\%), and the presence of primary sclerosing cholangitis is recognized only because of abnormally elevated blood

${ }^{1}$ Médico general, graduada de la Universidad de Ciencias Médicas (UCIMED), médico investigadora independiente, San José, Costa Rica. Código médico: 14292.

acunak872@gmail.com

levels of liver enzymes that often are performed along with a routine physical examination.

KEY WORDS: cholangitis, gall bladder, fibrosis, extrahepatic, liver, intestine. 


\section{INTRODUCCIÓN}

La Colangitis esclerosante primaria (CEP) es una enfermedad hepática colestásica crónica, caracterizada por inflamación progresiva y fibrosis de los conductos biliares intra y extrahepáticos, generando colestasis, fibrosis hepática progresiva y eventualmente a cirrosis descompensada en la mayoría de los pacientes en 10-15 años.

Además debería de ser considerada una condición premaligna por el riesgo aumentado que tienen los pacientes de cáncer hepatobiliar y colorectal y siendo la causa de mortalidad más importante en estos pacientes.

Por su etiopatogenia, aún se desconoce una terapia médica efectiva para esta enfermedad y por la naturaleza de daño biliar y hepático progresivo en la mayoría de los pacientes en 10-15 años del diagnóstico inicial, presentan hipertensión portal y falla hepática por tanto algunos pacientes requieren un trasplante hepático por su condición, siendo este el único tratamiento disponible para el tratamiento de CEP avanzada.

\section{EPIDEMIOLOGÍA}

Aproximadamente $60 \%$ de los pacientes son masculinos con una edad media de 41 años. La incidencia esta entre 0-1.3 casos en 100.000 personas por año y la prevalencia esta entre $0-16.3$ casos en 100.000 personas.

Estudios en el norte de Europa ha documentado un incremento en la incidencia y la prevalencia, sin embargo se desconoce si este aumento se debe a un verdadero aumento en la incidencia de la enfermedad o se debe a una mejor detección por la disponibilidad de mejores equipos diagnósticos como la colangiopancreatografía retrograda endoscópica (CPRE) y la colangiopancreatografía por resonancia magnética (MRCP).

En los EEUU hay aproximadamente 29000 pacientes con esta enfermedad. En países desarrollados CEP es el factor de riesgo más común para colangiocarcinoma, se cree que el riesgo es 400 veces mayor que en la población normal.

En pacientes con CEP el riesgo de colangiocarcinoma es $2 \%$ y la incidencia acumulativa en 30 años es $20 \%$.

Los pacientes masculinos con esta enfermedad tienen un aumento de la mortalidad 4 veces más, en comparación con pacientes del mismo sexo y edad.

\section{ETIOLOGÍA}

La causa y la patogenia aún son desconocidas, sin embargo se han aceptado los factores genéticos $y$ ambientales contribuyen al desarrollo de la enfermedad, la evolución de la misma y sus consecuencias.

Se ha asociado con Ell $(60-80 \%$ de los pacientes tienen ambas condiciones) y también se conoce por ser un factor de riesgo para el cáncer de colon, vías biliares y vesícula biliar.

\section{PATOGÉNESIS}

Se cree que la patogénesis es una enfermedad inmuno-mediada compleja, en vez de una verdadera enfermedad autoinmune por la falta de características clásicas como predominio en sexo masculino, falta de respuesta a terapia 
inmunosupresora y falta de autoanticuerpos.

El factor hereditario y ambiental están involucrados en la causa y la patogénesis de CEP.

La hipótesis más comúnmente aceptada es que en pacientes con predisposición genética, un insulto inicial a los colangiocitos por exposición ambiental a toxinas, alteración vascular o agentes infecciosos (translocación bacteriana) resulta en un daño inmuno-mediado persistente con destrucción progresiva de los conductos biliares generando colestasis crónica y fibrosis progresiva.

La evidencia inicial de susceptibilidad genética deriva de estudios que mostraron que pacientes con familiares que tienen CEP tiene 9-39 veces más riesgo de CEP que la población en general.

Se ha encontrado que el locus HLA en el cromosoma 6p21 contiene regiones asociados con mayor susceptibilidad a esta enfermedad. CEP está asociada con HLA clase I, II y III. Existe una asociación importante con los HLA-DR3 y HLA-B8. También se han encontrado polimorfismos de genes no HLA, que codifican para la molécula de adhesión intracelular 1 , factor de necrosis tumoral y metaloproteinasa de matriz 3 , esta última tiene un rol en la progresión de CEP por que regula la activación inmune y la fibrosis.

También se han asociado con genes de la cadena de interleucina 2 con aumento de la susceptibilidad para CEP. Esta información sugiere que la inmunidad adaptativa y células $T$ reguladoras son importantes en la patogénesis de la enfermedad. Aún se desconoce el rol que tienen las células $B$, pero se ha descrito aumento de $\lg G 4$ en $10 \%$ de los pacientes.

Con respecto a los desencadenantes ambientales, se ha visto que el tabaco es un factor protector y también pacientes con el CEP consumen menos café. Se ha visto que estos pacientes tienen consumo menor de carne y mayor cantidad de hamburguesas y carnes rojas. Con esto se puede demostrar que la dieta y los métodos de preparación de la comida pueden contribuir al desarrollo de la enfermedad, tal vez por cambios en la flora intestinal.

Se ha postulado una fuerte asociación entre el CEP y el Ell, se basa en que las bacterias bacterianas en el intestino sufren una translocación por el intestino inflamado y el alcanzan el hígado a través de la circulación del portal e inician una respuesta colangiocótica aberrante. También se ha visto que es humano, hay una variante genética de fucosil transferasa 2, una molécula que se puede expresar en el intestino y los colangiocitos, en la síntesis de un antígeno $\mathrm{H}$ oligosacárido, que sirve como medio de unión para algunas bacterias intestinales.

\section{CLÍNICA}

Es insidiosa, la mayoría de los pacientes (44-56\%) son asintomáticos por lo que el diagnóstico se realiza cuando se detectan pruebas hepáticas anormales y / o descubrimiento incidental de conducto intrahepatico dilatado.

El $17 \%$ de los pacientes asintomáticos tiene cirrosis en la biopsia hepática al momento del diagnóstico.

En los pacientes sintomáticos, los síntomas que predominan son:

- Dolor abdominal (20\%) 
- Prurito $(10 \%)$

- Ictericia $(6 \%)$

- Fatiga (6\%)

Los signos más frecuentes al momento del diagnóstico son:

- Hepatomegalia (44\%)

- Esplenomegalia (39\%)

Enfermedades de la vesícula biliar en pacientes con CEP como cálculos, pólipos y cáncer. Se ha reportado cálculos en un $25 \%$ de los pacientes y las mujeres en un $6-14 \%$, en donde el $60 \%$ de las masas corresponden adenocarcinomas.

Cambios abruptos en la clínica como ictericia de inicio reciente, fiebre, pérdida de peso, pruebas de función hepática anormal como elevación de fosfatasa alcalina, bilirrubina 0 ambos, con 0 sin progresión de los niveles séricos de CA $19-9$, se debe pensar en realizar una evaluación adicional (con ultrasonografía o resonancia magnética del hígado).

\section{DIAGNÓSTICO}

Criterios diagnósticos incluyen niveles de fosfatasa alcalina aumentados que persisten por más de 6 meses, datos de estenosis en la vía biliar documentado por MRCP o CPRE y exclusión de causas de colangitis esclerosante secundaria (CES).

ALT y AST aumentan 2-3 veces el límite superior normal.

La bilirrubina esta normal en la mayoría, los aumentos hacen pensar en enfermedad avanzada, coledocolitiasis superpuesta o malignidad.

La biopsia hepática no es necesaria para el diagnóstico a menos de que haya sospecha de CEP de conductos pequeños o solapamiento con hepatitis autoinmune, cuando las enzimas hepáticas están elevadas de manera anormal.

Además de histología típica que es el patrón de fibrosis periductal en "piel de cebolla", con solo células inflamatorias, solo está presente en menos del $20 \%$ de los pacientes y también se puede encontrar en el CES.

No se han identificado biomarcadores para predecir la progresión del CEP. Se ha visto que 102 años después del diagnóstico, niveles séricos de fosfatasa alcalina menor de 1.5 veces el límite superior normal tiene mejor desenlace que los que tienen la fosfatasa alcalina mayor de 1.5 veces el límite superior normal.

La colangiografía es el estándar de oro para el diagnóstico del CEP, se caracteriza por estenosis cortas, anulares, multifocales que se alternan con segmentos normales o levemente dilatados. MRCP es mejor que CPRE al menos que tenga que realizar una intervención biliar, ya que CPRE se asocia con colangitis bacteriana $y$ pancreatitis.

Hay subtipos de CEP, el tipo clásico que involucra todo el árbol biliar está presente en $90 \%$ de los pacientes, y solo $5 \%$ de los pacientes tiene afectados los conductos biliares intrahepaticos de forma aislada. La clínica y la progresión dependen del subtipo, por ejemplo, el CEP de conductos pequeños tienen mejor que el subtipo clásico.

Dado que la asociación tiene los pacientes con CEP con EEI (87\% con colitis ulcerativa y $13 \%$ con enfermedad de Crohn), se debe realizar colonoscopia a todos los pacientes recién diagnosticados, ya que el riesgo de cáncer de colon es estos pacientes es 4 veces mayor que en pacientes con Ell 
aislada y 10 veces mayor que la población en general.

Los pacientes con CEP tienen un 10$15 \%$ de riesgo de desarrollar colangiocarcinoma, por lo que se realiza un ultrasonido hepático anual y niveles séricos de CA 19-9.

\section{TRATAMIENTO}

El tratamiento para estos pacientes es complejo. Requieren el tratamiento de la enfermedad hepática primaria y las condiciones coexistentes, además de la terapia subsecuente para las complicaciones de la enfermedad hepática avanzada.

Aún no se conoce un tratamiento médico efectivo para CEP, un pesar de todos los estudios que se han realizado. El ácido ursodesoxicolico (UDCA), epímero del ácido quenodeoxicolico es el que más se ha estudiado, la mejora de la secreción hepatobiliar, el hepatoprotector, tiene propiedades inmunomoduladoras y es bastante efectivo en el manejo de la cirrosis biliar primaria. Se ha visto que UDCA disminuye el riesgo de cáncer colorrectal, por lo que se recomienda el uso en pacientes con CEP y Ell, como quimio prevención.

Actualmente se considera razonable el uso de UDCA 13-15mg / kg por 6 meses y monitorizar los niveles enzimáticos del paciente. $\mathrm{Si}$, el paciente no mejora los niveles de fosfatasa alcalina en ese momento entonces se sugiere descontinuar el tratamiento o someterse a otras pruebas terapéuticas.

Nuevos tratamientos se han evaluado como el ácido obeticolico, es un elemento semi-sintético de ácido quenodeoxicolico y un ligando para el receptor $\mathrm{X}$ farsenoide que tiene efecto antifibrotico. Uso de simtuzumab, un anticuerpo monoclonal contra Loxl2, una enzima que funciona como proteína profibrotica. También el "ácido ursodeoxicolico 24 nor", es un ácido biliar sintético que tiene un efecto benéfico en pacientes con fibrosis hepática.

También se están realizando estudios en un inhibidor para el transportador apical de ácidos biliares dependientes de sodio en el íleon, para reducir la exposición de los colangiocitos a ácidos biliares tóxicos. El trasplante de heces de microbiota se ha estado planteando, por el rol que tiene la flora intestinal en el desarrollo del CEP. Por la naturaleza progresiva de esta enfermedad, hace aproximadamente $40 \%$ de los pacientes requieren trasplante hepático, la cual es la única modalidad terapéutica disponible en pacientes con CEP avanzada. Sobrevida a 1 año después de trasplante es $85 \%$ y a 5 años es $72 \%$. Sin embargo, la enfermedad puede recurrir en $20-25 \%$ de los pacientes.

Un estudio demuestra que la colectomía antes del trasplante hepático en pacientes con Ell, puede disminuir la recurrencia después del trasplante.

\section{SEGUIMIENTO}

Aunque en los pacientes con CEP y Ell se han dado el trasplante hepático, deben ser sometidos a una colonoscopia anual con biopsia para seguimiento, por el aumento de cáncer de colon. En pacientes que no tienen datos de Ell, deben tener colonoscopia cada 5 años.

Se debe realizar ultrasonido de la vesícula biliar para detectar pólipos $u$ otras masas, pacientes con cualquier tipo de masa en la vesícula biliar deben tener colecistectomía. 


\section{BIBLIOGRAFÍA}

1. Konstantinos N. Lazaridis, MD. (2016). Colangitis esclerosante primaria. The New England Journal of Medicine, 375, 1161-1170.

2. Siddharth Singh. (2013). Colangitis Esclerosante Primaria: Diagnóstico, Pronóstico y Manejo. Clinical Gastroenterology and Hepatology, 11, 898-907.

3. Nieun Seo, MD. (2016). Colangitis esclerosante: características clínico-patológicas, espectro de imágenes y enfoque sistémico para el diagnóstico diferencial. Korean Journal of Radiology, 17, 25.

4. Mark Feldman. (2016). Sleisenger y la enfermedad gastrointestinal y hepática de Fordtran. Philadelphia, PA: Saunders / Elsevier.

Recepción: 15 Junio de 2018

Aprobación: 10 Agosto de 2018 